REVIEW ARTICLE

Volume 10 Issue 12018

DOI: 10.21315/eimj2018.10.1.3

ARTICLE INFO

Submitted: $26-02-2018$

Accepted: 03-03-2018

Online: 30-03-2018

\section{The Application of Learning Taxonomy in Anatomy Assessment in Medical School}

\author{
Siti Nurma Hanim Hadie
}

Department of Anatomy, School of Medical Sciences, Universiti Sains Malaysia, Kelantan, MALAYSIA

To cite this article: Hadie SNH. The application of learning taxonomy in anatomy assessment in medical school. Education in Medicine Journal. 2018;10(1):13-23. https://doi.org/10.21315/ eimj2018.10.1.3

To link to this article: https://doi.org/10.21315/eimj2018.10.1.3

\title{
ABSTRACT
}

It is generally accepted that assessment is a single powerful tool that drives students' learning. However, assessment of anatomy subject in medical curriculum is disputable as it focusses more on testing the low order thinking skills. In medical education context, it is of paramount importance to align the assessment with the curriculum (i.e., learning outcomes) and teaching methods as to enhance learning through a meaningful learning experience. Hence, the use of learning taxonomy should be emphasised in designing a proper and suitable assessment for anatomy subject. Among the most commonly used taxonomies in higher education, are the Bloom's taxonomy, Miller's pyramid, SOLO taxonomy, Krathwohl's taxonomy of affective domain, and Simpson's psychomotor domain. However, being a core basic medical subject with high cognitive input, it is often difficult to achieve contextual learning in anatomy through application of these taxonomies. Therefore, with raising concern of lack in the evaluation of higher order thinking skills, affective and psychomotor domains, the anatomy assessment in modern medical curriculum have been improvised to address the aforementioned issues. The modern form of assessment in anatomy facilitates the contextual learning with beneficial attributes gained by students including better understanding of anatomy knowledge, synthesis of anatomical concept, appreciation of the clinical importance of anatomy, increases communication skills, and increase in the confidence level.

Keywords: Anatomy assessment, Learning taxonomy, Educational outcomes, Constructive alignment

Siti Nurma Hanim Hadie, Department of Anatomy, School of Medical Sciences, Universiti Sains Malaysia, 16150 Kota Bharu, Kelantan, Malaysia | Email: snurma@usm. my

\section{INTRODUCTION}

It is generally accepted that assessment is a single powerful tool that drives students' learning (1-3). In higher education context, assessment shapes students' experience and behaviour during teaching, learning and revision sessions (4). In order to be aligned with the educational objectives, assessment in medical curriculum is often conducted through various methods to accommodate different outcome performance $(1,2)$. Nonetheless, it is not uncommon to have a poorly-designed assessment that is out of alignment with the curricular goal, thus lead to deterioration of the learning outcomes (5, $6)$.

Assessment of anatomy subject in medical school is still disputable since 
it focuses more on testing the low order thinking skills. Unlike other basic medical subjects, it is often difficult to test for higher cognitive levels such as knowledge application, analysis and evaluation in anatomy assessment especially when it is conducted on the pre-clinical years students (7). Having said that, anatomy remains as an important medical subject with high clinical relevancy, in which the deficiency of this knowledge has been reported to cause various medico-legal problems (810). Looking at the importance of anatomy knowledge in relation to competency of medical graduates, more emphasis is being given to improve the anatomy assessment by anatomists and medical educationists over the last decade $(7,8,11,12)$.

Being a core basic medical subject with high cognitive input, it is almost impossible to achieve contextual learning in anatomy education environment although there is a perceived need to promote conceptualisation, retention and application of the basic and clinical anatomical sciences knowledge (13-15). Even though there are vast changes in the anatomy education environment, this mostly confines to improving the methods of teaching and learning (16-21). The assessment component is infrequently explored. Ideally, an anatomy assessment should not only concentrate on the low-order cognitive thinking skills, but it should be able to promote cognitive application of basic and clinical anatomy knowledge, cognitive synthesis of separate anatomical concept, demonstrate safe clinical procedures pertaining to anatomical structures and general development of professionalism (8, 22-24). Hence, future anatomy assessment should be tailored to the expected educational outcomes beyond the level of cognitive domain by adopting different types of learning taxonomy frameworks for learners' assessment in medicine $(23,25)$.

\section{LEARNING TAXONOMY IN ANATOMY EDUCATION}

Learning taxonomy refers to a multi-tiered model that classifies the different levels of learning domains, which can guides the academic members to plan for their teaching and assessment so that it can be aligned with the educational objectives. Among the most commonly used taxonomies in higher education, are the Bloom's taxonomy, Miller's pyramid, SOLO taxonomy, Krafthwohl taxonomy of affective domain and Simpson's psychomotor domain (12, $22,26-28)$.

Despite that, with raising concern of lack in the evaluation of higher order thinking skills, affective domain and psychomotor domain in anatomy assessment, anatomy educators had started to venture into research that study on the possibilities of imposing higher cognitive, affective and psychomotor domains into the students' learning using the available taxonomies $(7,12,14)$. For instance, Phillips and colleagues conducted a research in attempt to categorise the different levels of cognitive domains of the students on radiological anatomy using a revised version of Bloom's taxonomy (12). They reported that their assessment is valid and reliable in evaluating the different depths of cognitive processes, whereby had directed their vision to improve their radiological anatomy teaching in the future. Apart from that, Integrated Anatomy Practical Paper (IAPP) exams that is being practiced by the Brighton and Sussex Medical School proofs that it is not impossible to assess the higher order thinking skills in anatomy knowledge and application if element of vertical and horizontal integration is strongly emphasised (7). The IAPP, which consist of combination of the old 'spotter' practical exam and the Objective Structures Clinical Examination (OSCE) is designed in such that can test all level of Bloom's Taxonomy of Educational Objectives (7). 
Apart from that, element of applying different level of cognitive, affective and psychomotor domains are also being applied in the teaching and learning activities although the hierarchical levels are not clearly spelled out. For instance, Yale School of Medicine (YSM) has outlined five learning objectives into their clinically-engaged anatomy course which include: (a) acquire anatomical knowledge; (b) develop clinical reasoning; (c) develop spatial reasoning; (d) explore structurefunction relationship; and (e) develop clinical professionalism (29). Although the hierarchical level was not elaborated, these objectives show application of different levels of cognitive domains with additional emphasis on affective attribute. Apart from that, effort has been made to categorise the different levels of cognitive, affective and psychomotor domains in facilitating the students' learning in anatomy. An example of this is an assessment that is used in the investigative approach to anatomy laboratory at Mohawk Valley Community College, New York (30).

\section{ANATOMY ASSESSMENT IN CONVENTIONAL MEDICAL CURRICULUM}

In a conventional medical curriculum, anatomy is traditionally assessed through written, practical and oral examinations. This involved mainly essay question, multiple choice questions (MCQ), and practical examination. Essay question is used simply because it is easy to set. However, this type of question is difficult to mark and has low reliability (31). In contrast, MCQ is more reliable, easy to mark and very objective $(2,31)$. Nevertheless, this type of question usually tests for low order thinking skills since it only directs the students for factual recall $(2,31)$. Practical examination, which can either be in written or free-response format, is often carried out as summative assessment in the form of "spotters" consisting of stream of prosected specimens, cadaveric dissection, radiological images and microscopic histological slides (3234). This type of question requires the students to identify certain structures and recall the factual information pertaining to the structures with little integration being emphasised. Apart from that, oral examination or viva voce is used in some medical schools with expectation that it could test for knowledge acquisition and retention. However, this type of question is said to have low inter-rater reliability and depends on the students' emotional status during the assessment (31). In addition to that, completion of cadaveric dissection to the satisfaction of lecturers is sometimes regarded as formative assessment in gross anatomy subject.

Most of the time, anatomy assessment in a conventional medical curriculum focuses on testing the theoretical part rather than the application of the anatomy knowledge. Much emphasis is given on the fine details, nomenclature and terminology during the assessment although these seem to be not significant for future practice (35). In other words, the assessment was designed to accommodate the cognitive aspect without imposing any weightage on the affective and psychomotor domains. This reflects that anatomy assessment in traditional medical curriculum was previously conducted without relying on proper educational outcomes and it catered only for ranking and grading $(35,36)$.

In response to this type of assessment, anatomy inputs are delivered through didactic lectures and cadaveric dissection $(15,37,38)$. The teaching session becomes very content-based and teacher-centred (15). The students have little control on the learning process and would only learn based on what will be assessed (3). This type on conventional teaching and assessment has influenced students' learning. With increase cognitive load and workload during lecture and dissection classes respectively, the students usually adopt the surface learning approaches such as memorisation and repetition $(9,39-42)$. On top of that, some 
students relied on the quality of teaching received for learning anatomy (43).

Although the drawbacks of conventional anatomy teaching and assessments are mainly anecdote rather than relying on empirical research, great concerns are being addressed by the new generation medical educationists with regard to the quality of graduates produced by the conventionalbased medical curriculum. Anatomy educators in general agreed with the idea of incorporating other elements in anatomy teaching and assessment to foster other attributes of graduates (44). However, this must be conducted without jeopardising the importance of having sufficient anatomy knowledge $(45,46)$.

\section{ANATOMY ASSESSMENT IN MODERN CURRICULUM}

In response to the situation mentioned earlier, there has been a major revamp in the anatomy curriculum with greater emphasis on improving the teaching and learning methods (44). Following the introduction of problem-based learning (PBL), and Student-centred, Problem-based, Integrated, Community-based, Elective and Systematic (SPICES) model, many medical schools started to adopt the problem-based, systembased and integrated curriculum rather than traditional-lecture-based curriculum $(37,38$, 43). As a result, there has been reduction in anatomy teaching hours, reduction in the anatomy content in the curriculum, less lecture delivery, abandonment of cadaveric dissection and incorporation of technology into anatomy teaching $(18,37$, $38,44,47)$. Unfortunately, apart from minor modification, the assessment component remained unexplored until the last decade.

The written and practical examinations are still widely used to assess anatomy knowledge in many medical schools. However, with better insight of the impact of assessment, greater concern is given in choosing and constructing a suitable and proper exam questions so that it can fulfilled the expected attributes of a graduate as outlined by many learning taxonomy. Miller and colleagues highlighted that anatomy questions should be developed in such a manner that can foster analytical thinking rather than encouraging simple memorisation (30). An example of this is the anatomy assessment conducted by the College of Medicine and Medical Sciences (CMMS) at the Arabian Gulf University (11).

In CMMS, the summative and formative anatomy assessments are designed to match the educational output of their problembased curriculum, in which elements of vertical and horizontal integration of themes are being incorporated (11). CMMS uses several methods of anatomy assessment in order to assess different learning domains which include knowledge, skills and attitude. The students are continually assessed during each PBL session through a structured evaluation that embraces group dynamic, brainstorming, identification of learning needs, information gathering, integration of knowledge, participation in group discussion, presentation and problem solving. The students are formatively assessed during their learning session at anatomy museum, during which, they are required to answer several MCQs and miniproblems followed by receiving feedback by the faculty members. As for the end of each unit, the students will be assessed through MCQs, Patient Management Problem (PMP) questions and Objective Structured Practical Examination (OSPE), which are carefully prepared and vetted under consultation of other basic sciences and clinical content experts.

For MCQs, extra emphasis is given to ensure appropriate distribution of difficulty index, relevance to main theme of learning objectives and integration of the components of the items. The stem of the questions is in the form of clinical scenario and the items include mixture of macroscopic, microscopic developmental, imaging and surface-anatomy concept. Whilst, the PMP is in the form of short- 
answer questions that are used to assess students' ability in correlating basic and clinical sciences pertaining to the problem given (11). It also assesses the capability of students in solving and managing the clinical problems. Students are provided with brief clinical scenario, which may also include laboratory investigation, radiographic images and photograph of specimens. Following that, a set of questions on knowledge of related basic sciences including anatomy and appropriate clinical related application will be asked. As for the OSPE questions, CMMS has put more emphasis on testing the psychomotor skills of the students and integration of knowledge rather than pure identification and recall. The OSPE is designed in such a way that students would need to perform practical task that have strong relationship with anatomical structures, such as suturing and intravenous injection. Apart from that, anatomical stations using wet specimens, plastinated specimens, models, radiographic images, clinical instruments and histological slides are also tested through vertically and horizontally integrated questions. CMMS's anatomy assessment shows that anatomy can be contextually learned through effective integration of factual knowledge and analysis of problem solving (11). Almost the similar form of written assessment which includes MCQs, short essay questions and OSPE are also being practiced by the College of Medicine, Al-Faisal University, Riyadh (24).

In addition to that, multiple answer and extended matching questions are used in the anatomy assessment of YSM. This type of questions are used to evaluate students' ability in combining information from multiple sources and images (29). Apart from that, YSM utilises the clinicalintegrated MCQs in their "anatomy longterm effectiveness examination" as formative assessment to their clinical year students (29). From this assessment, students can obtain immediate feedback through the computer-generated results after the test.
In 1996, the faculty members of Southern Illinois University School of Medicine started to improvise their method of human gross anatomy assessment to their first year medical students (8). They introduced a 30 minutes oral exposition exam of axial and appendicular anatomy to replace the traditional written and practical exams (8). This exam was reported to be carefully described and goal directed. At the beginning of the academic year, each student received the details of the objectives of the assessment, criteria for evaluation and clear direction of what are expected in terms of content and behaviour. During teaching sessions, the students a required to utilise the cadaver that he or she had dissected, in whom they learn about nomenclature, position, function, spatial relationship and clinical significance with prior demonstration by the faculty member on the subject matter. Apart from that, the students were required to use the cross-sectional cadavers, radiographs' film and articulated and disarticulated skeleton to facilitate their information gathering process.

At the end of the semester, each student need to present two sessions of 30 minutes oral exposition to his or her peers with the presence of a faculty member. In this session, the students would demonstrate specific details on cadaver, radiographs film, cross sections and models with strong emphasise on clinical application, function, nomenclature and spatial relationship. In addition to the two oral exposition exams, the students were also required to complete the total dissection of the cadaver as their formative assessment. The faculty members highlighted that their assessment facilitates the contextual learning with beneficial attributes gained by their students including better understanding of anatomy knowledge, synthesis of anatomical concept, appreciation of the clinical importance of anatomy, increases communication skills and increase in the confidence level (8). Having said that, this type of assessment may not be feasible nowadays due to logistic factors such as shortage of cadavers (38). 
Another alternative method to traditional assessment in anatomy education is the peer assessment, as recommended by the UK General Medical Council Education Committee (36). In addition to acquiring knowledge and understanding of the subject matter, peer assessment enhances skills in listening, presenting, negotiating, making objective judgements on the value of one's work and providing constructive feedbacks $(48,49)$. An example of peer assessment in anatomy education is the assessment of gross anatomy knowledge in large medical anatomy classes conducted by the Queen's University of Belfast and Strathclyde University of Glasgow (36). This assessment was conducted to the first year medical students, who were required to undertake three individual project assignments in anatomy that need to be presented in the form of 1,000 words report and short oral presentation. The content of the assignments is confined to various aspect of anatomy that is related to clinical cases presented to them. At the beginning of the program, the students were given full briefing on the assignments and assessment, which include the formulation of the marking scheme achieved through negotiation between students and lecturers. The completed assignment will be then rated by the colleagues in a proper tutorial session with the presence of a faculty member. Each students needs to give marks to the assignment according to the agreed checklist and provide constructive feedback on the written assignment to justify their mark.

Similarly, Wright State University School of Medicine, Dayton, Ohio also utilises peer assessment ratings for anatomy and embryology courses following team-based learning session in small groups (50). Each student will need to give individual score to their peers' performance on the task allocated to their groups, which contributes to the final marks. Apart from that, the students will also rate their peers in terms of cooperative learning skills, self-directed learning and interpersonal skills as the formative evaluation. Anonymous ratings and written feedback will be returned to each student for further improvement. It is noteworthy to highlight that the effects of peer assessment rating is more towards enhancing students' learning through constructive feedback rather that the getting a reliable marks in the summative assessment $(36,51)$. In fact, peer assessment is a good model of assessment in providing constructive feedback to a large group of students $(36,52)$.

In addition to the different types of assessment mentioned above, cadaveric dissection is often considered to be part of formative and sometimes as summative assessment in some medical schools that are still doing cadaveric dissection as their teaching method (53). While arguments remain on the feasibility of cadaveric dissection in modern anatomy education, the importance of cadaveric dissection in acquiring core anatomy knowledge, enhancing spatial ability and developing students psychosocial entity and instilling professionalism is undisputable $(54,55)$. However, anatomy educators are adopting new ways of assessing students' performance on cadaveric dissection by incorporating supervisor's rating on the well-defined goals (i.e., knowledge acquisition and structural identification) and peers' rating on students' team-work quality and self-directed learning $(53,55)$.

The various types of anatomy assessments, domains measured in the assessment, hierarchical level according to available learning taxonomies and outcome of the assessments are summarised in Table 1. 
Table 1: Various types of anatomy assessments, learning domains in relation to Bloom's taxonomy, Krathwohl's affective domain and Simpson's psychomotor domain, and educational outcomes

\begin{tabular}{|c|c|c|c|c|}
\hline Curriculum & Type of assessment & $\begin{array}{l}\text { Learning } \\
\text { domain }\end{array}$ & Hierarchical level & Outcome \\
\hline \multirow{4}{*}{$\begin{array}{l}\text { Traditional/ } \\
\text { Conventional } \\
\text { curriculum } \\
\text { (subject-based) }\end{array}$} & $\begin{array}{l}\text { Multiple choice } \\
\text { questions }\end{array}$ & \multirow[t]{4}{*}{ Cognitive } & \multirow{4}{*}{$\begin{array}{l}\text { Remembering, } \\
\text { Understanding } \\
\text { (Bloom's taxonomy) }\end{array}$} & \multirow{4}{*}{$\begin{array}{l}\text { Teacher-centred } \\
\text { and content- } \\
\text { based learning, } \\
\text { stressful learning } \\
\text { environment (high } \\
\text { workload/high } \\
\text { cognitive load), } \\
\text { superficial learning } \\
\text { approach and } \\
\text { poor knowledge } \\
\text { integration }\end{array}$} \\
\hline & Essay questions & & & \\
\hline & 'Spotter' practical exam & & & \\
\hline & Viva-voce exam & & & \\
\hline \multirow{10}{*}{$\begin{array}{l}\text { Modern } \\
\text { curriculum } \\
\text { (PBL-based/ } \\
\text { integrated) }\end{array}$} & $\begin{array}{l}\text { Multiple choice } \\
\text { questions }\end{array}$ & \multirow[t]{4}{*}{ Cognitive } & \multirow{4}{*}{$\begin{array}{l}\text { Remembering, } \\
\text { Understanding, } \\
\text { Applying, Analysing, } \\
\text { Evaluating (Bloom's } \\
\text { taxonomy) }\end{array}$} & \multirow{10}{*}{$\begin{array}{l}\text { Contextual and } \\
\text { collaborative } \\
\text { learning, clinical } \\
\text { integration of } \\
\text { anatomy knowledge, } \\
\text { cultivation of } \\
\text { soft skills and } \\
\text { professionalism }\end{array}$} \\
\hline & $\begin{array}{l}\text { Multiple answer } \\
\text { questions }\end{array}$ & & & \\
\hline & $\begin{array}{l}\text { Extended matching } \\
\text { questions }\end{array}$ & & & \\
\hline & Short essay questions & & & \\
\hline & $\begin{array}{l}\text { Objective structured } \\
\text { practical/Clinical } \\
\text { examination }\end{array}$ & Psychomotor & $\begin{array}{l}\text { Perception (Identify, } \\
\text { relate and integrate) } \\
\text { (Simpson's } \\
\text { psychomotor } \\
\text { domain) }\end{array}$ & \\
\hline & Oral exposition exam & \multirow[t]{3}{*}{ Cognitive } & \multirow{3}{*}{$\begin{array}{l}\text { Remembering, } \\
\text { Understanding, } \\
\text { Applying, Analysing, } \\
\text { Evaluating (Bloom's } \\
\text { taxonomy) }\end{array}$} & \\
\hline & $\begin{array}{l}\text { Integrated Anatomy } \\
\text { Practical Paper (IAPP) }\end{array}$ & & & \\
\hline & $\begin{array}{l}\text { Formative cadaveric } \\
\text { dissection }\end{array}$ & & & \\
\hline & & Psychomotor & $\begin{array}{l}\text { Perception, Set, } \\
\text { Guided response } \\
\text { (Simpson's } \\
\text { psychomotor } \\
\text { domain) }\end{array}$ & \\
\hline & & Affective & $\begin{array}{l}\text { Receiving, } \\
\text { Responding, } \\
\text { Valuing, Organising } \\
\text { (Krathwohl's } \\
\text { affective domain) }\end{array}$ & \\
\hline
\end{tabular}




\section{SUMMARY AND CONCLUSION}

This literature review reveals some important learning points. First, assessment remains superior to teaching method in influencing students' learning behaviour. Regardless of how effective the teaching is, students will pay more attention on how they will be assessed. Second, it is not impossible to incorporate high cognitive, affective and psychomotor domains in anatomy assessment. This can be achieved through vertically and horizontally integrated questions, which involved multidisciplinary approach. Third, the elements of affective domain in anatomy education are mainly achieved through formative assessment via peer and faculty ratings. Through this type of assessment, the students learn on effective timemanagement, soft skills, team-work, making good judgement and giving constructive feedback. Fourth, the available learning taxonomies can be fully utilised in designing the anatomy assessment although this seems to be not so straightforward. Acquisition of anatomy core knowledge should not be confused with acquisition of clinical skills and affective attributes.

In conclusion, a well-planed and properlydesigned assessment is important in achieving constructive alignment in anatomy education, which subsequently contributes to effective learning environment. It is imperative to highlight that anatomy educators in near future should work on to achieve a consensus on the best method in assessing anatomy knowledge through the best evidence in medical education. Since anatomy is a subject that imposes high cognitive inputs to the students, future effort should be made to create a separate learning taxonomy that can enhance students' spatial ability in learning anatomy core knowledge. Apart from that, creating a "stand-alone" taxonomy that incorporate all important learning domains in anatomy education can be the stepping-stone to improve the anatomy assessment.

\section{REFERENCES}

1. Epstein RM. Assessment in medical education. $\mathrm{N}$ Engl J of Med. 2007;356(4):387-96.

2. Godfrey R. Undergraduate examinations-a continuing tyranny. The Lancet. 1995;345(8952):765-7. https:/doi. org/10.1016/S0140-6736(95)90644-4

3. Lowry S. Assessment of students. BMJ. 1993;306(6869):51-4. https://doi. org/10.1136/bmj.306.6869.51

4. Bloxham S, Byod P. Developing effective assessment in higher education: a practical guide. New York: McGraw Hill Education; 2007.

5. Bloomfield L, Harris P, Hughes C. What do students want? The types of learning activities preferred by final year medical students. Med Educ. 2003;37(2):1108. https://doi.org/10.1046/j.13652923.2003.01430.x

6. Newble DI, Jaeger K. The effect of assessments and examinations on the learning of medical students. Med Educ. 1983;17(3):165-71. https://doi. org/10.1111/j.1365-2923.1983.tb00657.x

7. Smith CF, McManus B. The integrated anatomy practical paper: a robust assessment method for anatomy education today. Anat Sci Educ. 2015;8(1):63-73. https://doi. org/10.1002/ase. 1454

8. Clough RW, Lehr RP. Testing knowledge of human gross anatomy in medical school: an applied contextual-learning theory method. Clin Anat. 1996;9(4):263-8. https://doi.org/10.1002/(SICI) 1098 2353(1996)9:4<263::AID-CA9>3.0.CO;2-F

9. Moxham BJ, Plaisant O. Perception of medical students towards the clinical relevance of anatomy. Clin Anat. 2007;20(5):560-4. https://doi.org/10.1002/ ca. 20453 
10. Ellis H. Medico-legal litigation and its links with surgical anatomy. Surgery (Oxford). 2002;20(8):i-ii. https://doi.org/10.1383/ surg.20.8.0.14518

11. Chakravarty M, Latif NA, Abu-Hijleh MF, Osman M, Dharap AS, Ganguly PK. Assessment of anatomy in a problembased medical curriculum. Clin Anat. 2005;18(2):131-6. https://doi.org/10.1002/ ca. 20038

12. Phillips AW, Smith SG, Straus CM. Driving deeper learning by assessment: an adaptation of the revised Bloom's taxonomy for medical imaging in gross anatomy. Acad Radiol. 2013;20(6):784-9. https://doi.org/10.1016/j. acra.2013.02.001

13. Collins TJ, Given RL, Hulsebosch CE, Miller BT. Status of gross anatomy in the U.S. and Canada: dilemma for the $21 \mathrm{st}$ century. Clin Anat. 1994;7(5):275-96. https://doi.org/10.1002/ca.980070509

14. Bergman EM, Sieben JM, Smailbegovic I, de Bruin $\mathrm{ABH}$, Scherpbier AJJA, van der Vleuten CPM. Constructive, collaborative, contextual, and self-directed learning in surface anatomy education. Anat Sci Educ. 2013;6(2):114-24. https://doi.org/10.1002/ ase. 1306

15. Louw G, Eizenberg N, Carmichael SW. The place of anatomy in medical education: AMEE guide no. 41. Med Teach. 2009;31(5):373-86. https://doi. org/10.1080/01421590902825149

16. Lempp HK. Perceptions of dissection by students in one medical school: beyond learning about anatomy. A qualitative study. Med Educ. 2005;39(3):318-25. https://doi. org/10.1111/j.1365-2929.2005.02095.x

17. McNulty JA, Sonntag B, Sinacore JM. Evaluation of computer-aided instruction in a gross anatomy course: a six-year study. Anat Sci Educ. 2009;2(1):2-8. https://doi. org/10.1002/ase. 66
18. Ivanusic J, Cowie $B$, Barrington $M$. Undergraduate student perceptions of the use of ultrasonography in the study of "living anatomy". Anat Sci Educ. 2010;3(6):31822. https://doi.org/10.1002/ase. 180

19. Nicholson DT, Chalk C, Funnell WRJ, Daniel SJ. Can virtual reality improve anatomy education? A randomised controlled study of a computer-generated three-dimensional anatomical ear model. Med Educ. 2006;40(11):1081-7. https://doi. org/10.1111/j.1365-2929.2006.02611.x

20. Yiou R, Goodenough D. Applying problembased learning to the teaching of anatomy: the example of Harvard Medical School. Surg Radiol Anat. 2006;28(2):189-94. https://doi.org/10.1007/s00276-005-0062-z

21. McLachlan JC, Patten D. Anatomy teaching: ghosts of the past, present and future. Med Educ. 2006;40(3):243-53. https://doi. org/10.1111/j.1365-2929.2006.02401.x

22. Miller GE. The assessment of clinical skills/ competence/performance. Acad Med. 1990;65(9):S63-7. https://doi. org/10.1097/00001888-199009000-00045

23. Pangaro L, ten Cate O. Frameworks for learner assessment in medicine: AMEE guide no. 78. Med Teach. 2013;35(6):e1197210. https://doi.org/10.3109/014215 9X.2013.788789

24. Ganguly PK. Teaching and learning of anatomy in the 21 st century: direction and the strategies. The Open Medical Education Journal. 2010:5-10.

25. Brenner E, Chirculescu AR, Reblet C, Smith C. Assessment in anatomy. Eur J Anat. 2015;19(1):105-24.

26. Lister R, Simon B, Thompson E, Whalley JL, Prasad C. Not seeing the forest for the trees: novice programmers and the SOLO taxonomy. SIGCSE Bull. 2006;38(3):118- 22. https://doi. org/10.1145/1140123.1140157 
27. Biggs JB, Collins KF. Evaluating the quality of learning: the SOLO taxonomy (Structures of the observed learning outcome). London: Academic Press; 1982.

28. Krathwohl DR. A revision of Bloom's Taxonomy: an overview. Theory Into Practice. 2002;41(4):212-8. https://doi. org/10.1207/s15430421tip4104_2

29. Rizzolo LJ, Rando WC, O'Brien MK, Haims AH, Abrahams JJ, Stewart WB. Design, implementation, and evaluation of an innovative anatomy course. Anat Sci Educ. 2010;3(3):109-20. https://doi.org/10.1002/ ase. 152

30. Miller SA, Perrotti W, Silverthorn DU, Dalley AF, Rarey KE. From college to clinic: reasoning over memorization is key for understanding anatomy. Anat Rec. 2002;269(2):69-80. https://doi.org/10.1002/ ar. 10071

31. Fowell SL, Bligh JG. Recent developments in assessing medical students. Postgrad Med J. 1998;74(867):18-24. https://doi. org/10.1136/pgmj.74.867.18

32. Inuwa IM, Taranikanti V, Al-Rawahy $M$, Habbal O. Anatomy practical examinations: how does student performance on computerized evaluation compare with the traditional format? Anat Sci Educ. 2012;5(1):27-32. https://doi.org/10.1002/ ase. 254

33. Inuwa IM, Taranikanti V, Al-Rawahy M, Habbal O. Perceptions and attitudes of medical students towards two methods of assessing practical anatomy knowledge. Sultan Qaboos Univ Med J. 2011;11(3):383-90.

34. Shaibah HS, van der Vleuten CPM. The validity of multiple choice practical examinations as an alternative to traditional free response examination formats in gross anatomy. Anat Sci Educ. 2013;6(3):149-56. https://doi.org/10.1002/ase.1325
35. Osler W. Examinations, examiners, and examinees. The Dublin Journal of Medical Science. 1913;136(5):313-27. https://doi. org/10.1007/BF02964451

36. Heylings DJ, Stefani LAJ. Peer assessment feedback marking in a large medical anatomy class. Med Educ. 1997;31(4):281-6. https://doi.org/10.1111/j.1365-2923.1997. tb02926.x

37. Older J. Anatomy: a must for teaching the next generation. The Surgeon. 2004;2(2):79$90 . \quad$ https://doi.org/10.1016/S1479666X(04)80050-7

38. Turney BW. Anatomy in a modern medical curriculum. Ann $\mathrm{R}$ Coll Surg Engl. 2007;89(2):104-7. https://doi. org/10.1308/003588407X168244

39. Notebaert AJ. Student perceptions about learning anatomy. Iowa: The University of Iowa; 2009.

40. Sadler-Smith E, Evans C, Diseth $\AA$, Pallesen S, Hovland A, Larsen S. Course experience, approaches to learning and academic achievement. Education + Training. 2006;48(2/3):156-69. https://doi. org/10.1108/00400910610651782

41. Kreber C. The relationship between students' course perception and their approaches to studying in undergraduate science courses: a Canadian experience. Higher Education Research \& Development. 2003;22(1):57-75. https://doi. org/10.1080/0729436032000058623

42. Trigwell K, Prosser $M$. Improving the quality of student learning: the influence of learning context and student approaches to learning on learning outcomes. High Educ. 1991;22(3):251-66. https://doi.org/10.1007/ BF00132290

43. Pandey P, Zimitat C. Medical students' learning of anatomy: memorisation, understanding and visualisation. Med Educ. 2007;41(1):7-14. https://doi.org/10.1111/ j.1365-2929.2006.02643.x 
44. Drake RL. Anatomy education in a changing medical curriculum. Anat Rec. 1998;253(1):28-31. https://doi.org/10.1002/ (SICI) 1097-0185(199802)253:1<28::AIDAR1 1>3.0.CO;2-E

45. Fitzgerald JEF, White MJ, Tang SW, Maxwell-Armstrong CA, James DK. Are we teaching sufficient anatomy at medical school? The opinions of newly qualified doctors. Clin Anat. 2008;21(7):718-24. https://doi.org/10.1002/ca.20662

46. McKeown PP, Heylings DJA, Stevenson M, McKelvey KJ, Nixon JR, R McCluskey D. The impact of curricular change on medical students' knowledge of anatomy. Med Educ. 2003;37(11):954-61. https://doi. org/10.1046/j.1365-2923.2003.01670.x

47. Craig S, Tait N, Boers D, McAndrew D. Review of anatomy education in Australian and New Zealand medical schools. ANZ J Surg. 2010;80(4):212-6. https://doi. org/10.1111/j.1445-2197.2010.05241.x

48. Falchikov N. Product comparisons and process benefits of collaborative peer group and self-assessments. Assessment \& Evaluation in Higher Education. 1986;11(2):146-66. https://doi. org/10.1080/0260293860110206

49. Dochy F, Segers M, Sluijsmans D. The use of self-, peer and co-assessment in higher education: a review. Studies in Higher Education. 1999;24(3):331-50. https://doi. org/10.1080/03075079912331379935
50. Nieder GL, Parmelee DX, Stolfi A, Hudes PD. Team-based learning in a medical gross anatomy and embryology course. Clin Anat. 2005;18(1):56-63. https://doi.org/10.1002/ ca. 20040

51. Magin D, Helmore P. Peer and teacher assessments of oral presentation skills: how reliable are they? Studies in Higher Education. 2001;26(3):287-98. https://doi. org/10.1080/03075070120076264

52. Norcini JJ. Peer assessment of competence. Med Educ. 2003;37(6):539-43. https://doi. org/10.1046/j.1365-2923.2003.01536.x

53. Burgess AW, Ramsey-Stewart G, May J, Mellis C. Team-based learning methods in teaching topographical anatomy by dissection. ANZ J Surg. 2012;82(6):45760 . https://doi.org/10.1111/j.14452197.2012.06077.x

54. Pawlina W, Lachman N. Dissection in learning and teaching gross anatomy: rebuttal to McLachlan. The Anatomical Record Part B: The New Anatomist. 2004;281B(1):9-11. https://doi.org/10.1002/ ar.b. 20038

55. Heyns M. A strategy towards professionalism in the dissecting room. Eur J Anat. 2007;11(Supplement 1):85-9. 